\title{
Fetomaternal Outcome in Second Stage Caesarean Section
}

\author{
Bishal Khaniyal \\ ${ }^{1}$ Department of Obstetrics and Gynecology, Institute of Medicine, Teaching Hospital, Maharajgunj Medical Campus, Kathmandu, \\ Nepal.
}

\section{ABSTRACT}

Introduction: Second stage caesarean section is usually associated with the deeply engaged head, less liquor, and thinned out the lower uterine segment. This can lead to a high risk of maternal morbidities like an extension of the lower uterine segment incision, uterine atony, and injury to urinary bladder as well as neonatal morbidities such as birth asphyxia, NICU admission, and meconium aspiration syndrome. This study aims to observe the maternal and neonatal outcomes of caesarean delivery performed in the second stage of labor.

Materials and Methods: This was a retrospective study of the fetomaternal outcome of all women with singleton, a cephalic fetus at term delivered by caesarean section in the second stage of labor over one year at Tribhuwan University Teaching Hospital.

Results: During this study period, there were 4653 deliveries. A total of $2274(48.88 \%)$ were born by caesarean section, out of which 1739 (76.5\%) were elective and 535(23.5\%) were emergency. Among emergency LSCS 36(6.72\%) were performed in the second stage of labor. Most of the indications were nondescent of head 34(93.5\%) followed by intraoperative maternal complications (hematuria; $\mathrm{n}=14 ; 38.88 \%$ ). Postoperative maternal who had complications were prolong catheterization:14(38.88\%), postoperative fever : $10(27.77 \%)$, prolong hospitalization : $5(13.88 \%)$ . In perinatal complications meconium stain liquor: $10(27.77 \%)$, NNU admissions : $5(13.88 \%)$, Apgar score $<5$ at $5 \mathrm{~min}: 5(13.55 \%)$, NICU admission : 2(5.54\%), fresh stillbirth : $1(2.77 \%)$ were observed.

Conclusions: Caesarean sections done in the second stage of labor are associated with severe maternal and neonatal complications.

Keywords: Caesarean section; Labour; Complication; Maternal; Neonatal; Second stage of labor
Correspondence:

Dr. Bishal Khaniya

Teaching Assistant, Department of Obstetrics and Gynecology

Institute of Medicine, Teaching Hospital, Maharajgunj Medical Campus, Kathmandu Nepal. ORCID ID:0002-0002-7191-0955

Email: bishalkhaniya92@gmail.com

Submitted: $1^{\text {st }}$ May 2020

Accepted: $28^{\text {th }}$ June 2020

Source of Support: None Conflict of Interest: None

Citation: Khaniya B. Fetomaternal outcome in second stage caesarean section. NMJ 2020;3(1):279-81. DOI 10.3126/nmj.v3i1.28923

\section{INTRODUCTION}

The second stage of labor is a period from full cervical dilatation $(10 \mathrm{~cm})$ until the delivery of the fetus. The incidence of caesarean section has increased tremendously over the recent years. ${ }^{1}$ The Royal College of Obstetricians and Gynecologists (RCOG) reports that approximately $6 \%$ of caesarean sections for of lack of training and supervision for junior staff in second-stage decisionmaking, lack of expertise in difficult-assisted vaginal delivery and concerns related to litigious issues because of maternal and neonatal morbidity. ${ }^{1}$ Caesarean section at full dilatation is technically a more challenging procedure than CS in early labour. ${ }^{3}$ Second stage caesarean section is a difficult procedure as it is associated with the deeply engaged fetal head, less amount of liquor and thinned out the lower uterine segment, thus it can lead to high risk of maternal morbidities, such as tearing of the lower uterine segment, extension of the uterine incision, injury to the urinary bladder, postpartum pyrexia, prolonged catheterization, and hospitalization. ${ }^{4-7}$ Neonatal morbidities associated with the second stage CS are birth asphyxia, neonatal intensive care unit (NICU) admission, fetal birth injuries, hypoxic-ischemic encephalopathy, and even neonatal death. ${ }^{8,9}$ Hence, this study is 
being done to observe maternal and fetal complications among women undergoing caesarean section during the second stage of labor.

\section{MATERIALS AND METHODS}

This is the hospital-based retrospective study conducted in all patients who had been admitted to the Department of Obstetrics and Gynecology, Tribhuwan University Teaching Hospital, Kathmandu, Nepal between March 1, 2017, to February 29, 2018 AD. Permission for the study and ethical approval was obtained from the institutional review committee (IRC) of Tribhuvan University, Institute of Medicine ( IOM).

The data was obtained from the confinement book of the labor room, birthing centre, record section of the hospital. Women with a singleton fetus in a cephalic presentation at term ( $\geq 37$ weeks) who underwent CS at full dilatation were included for the study. Patients with comorbid conditions like diabetes and preeclampsia were excluded from the study. Women who underwent second stage caesarean sections were analysed in terms of indications, intraoperative complications, postoperative complications, and perinatal outcomes. Intraoperative complications like hematuria, uterine incision extension, and atonic postpartum hemorrhage were observed from procedure notes and patient charts. Postoperative complications like postoperative fever $\left(>100.4{ }^{\circ} \mathrm{F}\right)$, prolonged catheterization ( $>24$ hours), prolonged hospitalization ( $>72$ hours), and perinatal outcome were noted from the patient's chart. All the collected data were recorded and entered in the master chart. Data analysis was done using SPSS version 17.

\section{RESULTS}

During this study, there were 4633 deliveries, a total of 2274 (48.88\%) were born by the Lower segment Caesarean section (LSCS). Out of all LSCS cases, 1739 (76.5\%) were elective and $535(23.5 \%)$ were emergency LSCS. Out of emergency LSCS, $36(6.72 \%)$ were performed in the second stage of labor. The most common indications were non-descent of the head in the second stage of labor $34(93.5 \%)$. Fetal distress was an indication in the remaining $2(6.5 \%)$ cases. The maternal intraoperative complications were encountered in 20/36 patients. Blood-stained urine was seen in most of the women $14(33.88 \%)$, followed by uterine incision extension $(n=5 ; 13.88 \%)$ and B Lynch compression suture application was seen in the least of women $1(2.77 \%)$ with atonic postpartum hemorrhage.

Postoperative complications were observed in 34/36 cases. Among all postoperative complications most common was prolong catheterization due to hematuria ( $n=14 ; 38.88 \%)$ followed by postoperative fever and prolonged hospital stay $(\mathrm{n}=10 ; 27.77 \%$ each $)$.

Table 1 summarises the perinatal outcome. Most of the second stage caesarean section had baby weight $3.6 \mathrm{~kg}-4 \mathrm{~kg} \quad(83 \%)$. The most common fetal complications were meconium-stained amniotic fluid, seen in $27.77 \%$ cases. Two (5.55\%) babies were admitted Iiquor the Neonatal Intensive Care Unit for management of respiratory distress due to meconium aspiration syndrome. The least women only one $(2.77 \%)$ had a fresh stillbirth baby whose fetal heart rate before general anesthesia was less than 60 beats/ $\min$.
Table 1: Perinatal outcome among patients undergoing LSCS in the second stage of labour

\begin{tabular}{lll}
\hline Perinatal outcome & Case n (\%) \\
\hline Baby weight & $2.5-2.9$ & $2(5.55 \%)$ \\
& $3.0-3.5$ & $4(11.11 \%)$ \\
\hline Meconium stain liquor & $3.6-4.0$ & $30(83.33 \%)$ \\
\hline NNU admission & $10(27.77 \%)$ \\
\hline Apgar score<5 at 5 min & $5(13.88 \%)$ \\
\hline NICU admission & $5(13.88 \%)$ \\
\hline Fresh stillbirth & $2(5.55 \%)$ \\
\hline
\end{tabular}

\section{DISCUSSION}

Caesarean section in the second stage of labor is a technically difficult operation with distortion of maternal pelvic anatomy and deeply impacted fetal head in the maternal pelvis. The incidence of caesarean section at full dilatation is $6.72 \%$ in our study which is similar to the study conducted by Unterscheider J et al. ${ }^{1}$ The most common indication of the second stage caesarean section was non-descent of the head (93\%) in this study. In a study by Belay et $\mathrm{al}^{10}$, the most common indication of the second stage caesarean section was cephalopelvic disproportion $(48.5 \%)$. A retrospective study from Canada has shown that women delivered by caesarean sections at full dilatation of the cervix were 2.6 times likely to have intraoperative trauma. ${ }^{11}$ Difficult delivery of impacted head may be facilitated by an assistant pushing from below or by using a reverse breech delivery. ${ }^{12}$ In this study uterine incision extension as seen in $13.88 \%$, which is slightly higher compared to the other studies may be due to head delivered by assistant pushing from below. ${ }^{13}$ This might be because non-descent of the head with major caput and molding formation makes the delivery of the fetal head challenge. Atonic postpartum hemorrhage was seen in $2(5.54 \%)$ cases, which is slightly less than in the study done by Babre V M et al $(11.5 \%))^{13}$ The use of prophylactic uterotonics in the second stage Caesarean could have contributed to this decreased number of postpartum hemorrhage. Development of uterine atony and requirement of B-Lynch compression suture for refractory postpartum hemorrhage $(2.27 \%)$ was found in this study and can be due to the longer duration of labor resulting in uterine inertia. Other maternal operative complications seen in our study were hematuria in 14(38.88\%), febrile illness in $10(27.77 \%)$, prolong catheterisation $14(38.88 \%)$, prolong hospitalisation $5(13.88 \%)$.

Intra-operative fetal hypoxia is a serious complication associated with the second stage caesarean section, which may be due to strong uterine contraction or longer duration of caesarean section resulting from deeply engaged head and difficulty in delivery. Most of the second stage caesarean section had baby weight 3.6 $\mathrm{kg}-4 \mathrm{~kg}$ (number $83 \%$ ) in this study. Cephalopelvic disproportion might be the cause of non-descent of the head in the second stage of labor. The most common fetal complication was meconiumstained amniotic fluid, seen in $27.77 \%$ cases which is comparable to a study by Jayaram $\mathrm{J}$ et $\mathrm{al}^{14}(30.75 \%)$. This might be due to intra-operative fetal hypoxia caused by strong uterine contraction, which deeply impacted fetal head and longer duration of the second stage of labor. The NICU admission rate was $4.5 \%$ and the nursery admission rate was $15 \%$ in the study by Allen VN et al. ${ }^{11}$ which is similar to this study. Fresh stillbirth and perinatal deaths were recorded in $23(4.9 \%)$ and $7(1.5 \%)$, respectively in 
a study by Umbeli et al. ${ }^{15}$ But we had only one fresh stillbirth $(2.77 \%)$. Similarly, the same study reported $37(6.6 \%)$ cases with Apgar score less than five at five minutes while $5(12.88 \%)$ of babies had an Apgar score of $<5$ at $5 \mathrm{~min}$ in this study. It is not comparable may be due to the small sample size of the study. The Royal College of Obstetrician and Gynaecologists in the UK suggest that a consultant be present at all second stage LSCS to make an informed decision and to reduce complications arising from such operations.
Caesarean sections done in the second stage of labor is an undesirable situation associated with maternal and fetal complications. Second stage CS can be avoided by using partograph, rational use of oxytocin, proper and selective instrumental delivery, and lastly but most importantly the presence of senior and expert obstetricians in decision making. The second stage CS must be approached and conducted by an efficient team of doctors and other staff to get a healthy baby and a healthy mother.

\section{CONCLUSIONS}

\section{REFERENCES}

1. Unterscheider J, McMenamin M, Cullinane F. Rising rates of caesarean deliveries at full cervical dilatation: a concerning trend. Eur. J. Obstet. Gynecol. Reprod. Biol. 2011;157(2):141-4. Crossref

2. Thomas J, Paranjothy S. The national sentinel caesarean section audit report. National Sentinel Caesarean Section Audit Report. 2001. Website

3. McKelvey A, Ashe R, McKenna D, Roberts R. Caesarean section in the second stage of labour: a retrospective review of obstetric setting and morbidity. Journal of Obstetrics and Gynaecology. 2010;30(3):264-7. Crossref

4. Govender V, Panday M, Moodley J. Second stage caesarean section at a tertiary hospital in South Africa. The Journal of Maternal-Fetal $\&$ Neonatal Medicine. 2010 Oct 1;23(10):1151-5. Crossref

5. Sung JF, Daniels KI, Brodzinsky L, El-Sayed YY, Caughey AB, Lyell DJ. Cesarean delivery outcomes after a prolonged second stage of labor. Am. J. Obstet. Gynecol. 2007;197(3):306-e1. Crossref

6. Alexander JM, Leveno KJ, Rouse DJ, Landon MB, Gilber S,Spong $\mathrm{CY}$, et al. Comparison of maternal and infant outcomes from primary cesarean delivery during the second compared with first stage of labor. Obstet Gynecol. 200;109(4):917-21. Crossref

7. Selo-Ojeme D, Sathiyathasan S, Fayyaz M. Caesarean delivery at full cervical dilatation versus caesarean delivery in the first stage of labour: comparison of maternal and perinatal morbidity. Arch Gynecol Obstet. 2008;278(3):245-9. Crossref

8. Murphy DJ, Liebling RE, Verity L, Swingler R, Patel R. Early maternal and neonatal morbidity associated with operative delivery in second stage of labour: a cohort study. The Lancet.

\section{1;358(9289):1203-7. $\underline{\text { Crossref }}$}

9. Davis G, Fleming T, Ford K, Mouawad MR, Ludlow J. Caesarean section at full cervical dilatation. Aust NZ J Obstet Gynaecol. 2015;55(6):565-71. Crossref

10. Belay T, Yusuf L, Negash S. A comparative study on first stage versus second stage caesarean section on maternal and perinatal outcome. Ethiop Med J. 2014;52(1):1-8. Website

11. Allen VM, O'Connell CM, Baskett TF. Maternal and perinatal morbidity of caesarean delivery at full cervical dilatation compared with caesarean delivery in the first stage of labour. BJOG. 2005;112(7):986-90. Crossref

12. Fasubaa OB, Ezechi OC, Orji EO, Isabu PA, Okogbenin S, Okogbo FO, et al. Delivery of the impacted head of the fetus at caesarean section after prolonged obstructed labour: a randomised comparative study of two methods. J Obstet Gynaecol. 2002;22(4):375-8. Crossref

13. Babre VM, Bendre KR, Niyogi G. Review of caesarean sections at full dilatation. Int $\mathrm{J}$ Reprod Contracept Obstet Gynecol. 2017;6(6):2491-3. Crossref

14. Jayaram J, Mahendra G, Vijayalakshmi S. Fetomaternal outcome in cesarean sections done in second stage of labor. IJOG. 2016;3(1):514. $\underline{\text { Crossref }}$

15. Umbeli T, Ismail S, Kunna A, Elmahgoub A, Nasr A, Rabaa A. Maternal and neonatal complications associated with cesarean section in the second stage of labour. Merit research journal of medicine and medical sciences 2014;2(10);225-28. Website 